Case Report

\title{
Amniotic Band Syndrome, Perinatal Hospice, and Palliative Care versus Active Management
}

\author{
Shadi Rezai, ${ }^{1}$ Justin Faye, ${ }^{2}$ Annika Chadee, ${ }^{1}$ Sri Gottimukkala, ${ }^{3}$ Ruchi Upadhyay, ${ }^{1}$ \\ Carla Lara, ${ }^{1}$ Benamanahalli H. Rajegowda, ${ }^{4}$ Andrew D. Corwin, ${ }^{1}$ Rasila V. Lala, ${ }^{4}$ \\ Jessica Vernon, ${ }^{1}$ Dilfuza Nuritdinova, ${ }^{1}$ Stephen Chasen, ${ }^{1}$ and Cassandra E. Henderson ${ }^{1}$ \\ ${ }^{1}$ Department of Obstetrics and Gynecology, Lincoln Medical and Mental Health Center, 234 East 149th Street, Bronx, NY 10451, USA \\ ${ }^{2}$ St. George's University School of Medicine, True Blue, Grenada \\ ${ }^{3}$ Department of Obstetrics and Gynecology, Houston Methodist St. John Hospital, 18300 St. John Drive, Nassau Bay, TX 77058, USA \\ ${ }^{4}$ Department of Pediatrics, Lincoln Medical and Mental Health Center, 234 East 149th Street, Bronx, NY 10451, USA \\ Correspondence should be addressed to Shadi Rezai; shadi.rezai@nychhc.org \\ and Cassandra E. Henderson; cassandra.henderson@nychhc.org
}

Received 4 July 2016; Revised 14 August 2016; Accepted 4 September 2016

Academic Editor: Giovanni Monni

Copyright (C) 2016 Shadi Rezai et al. This is an open access article distributed under the Creative Commons Attribution License, which permits unrestricted use, distribution, and reproduction in any medium, provided the original work is properly cited.

\begin{abstract}
Introduction. Amniotic band syndrome and sequence are a relatively rare condition in which congenital anomalies occur as a result of the adherence and entrapment of fetal parts with coarse fibrous bands of the amniotic membrane. A large percentage of reported cases have an atypical gestational history. The frequency of this obstetric complication is not affected by fetal gender, genetic abnormality, or prenatal infection. Case. A 21-year-old, G1P0 female parturient at 18 weeks and 5 days with a single intrauterine gestation during a routine ultrasound evaluation was noted to have amniotic band sequence. The pregnancy was subsequently complicated by preterm premature rupture of membranes with oligohydramnios, resulting in a surviving neonate scheduled for rehabilitative treatment. Conclusion. Amniotic band syndrome is an uncommon congenital anomaly resulting in multiple disfiguring and disabling manifestations. Several theories are proposed with most involving early rupture of the amnion and entanglement of fetal parts by amniotic bands. This syndrome can be manifested by development of multiple malformations, with the majority of the defects being limb abnormalities of a disorganized nature, as in the case we present. In the absence of a clear etiology of consequential congenital abnormalities, obstetric management guidelines should use shared decision models to focus on the quality of life for the offspring.
\end{abstract}

\section{Introduction}

The clinical manifestations are primarily distal deformities, such as constriction of limbs and fingers, syndactyly, acrosyndactyly, phalangeal hypoplasia, pseudoainhum, and amputation of limbs and fingers $[1,2]$. There is a predilection for the hand, in particular the central digits, whereas the frequency and severity of thumb involvement are minimal $[3,4]$. The thumb is less vulnerable since it lies protected within the palm of the hand in utero, compared to the longer digits which are more exposed leading to amputations distal to the level of the proximal phalanx [3-6]. Multiple malformations such as clubfoot (30\% of patients), leg length discrepancies $(24 \%)$, other bone anomalies $(12 \%)$, special craniofacial defects such as cleft lip and palate (8\%), visceral and body wall defects, and anencephaly (5\%) have been detected in $70 \%$ of infants with the disorder [7-11].

\section{Case Presentation}

A 21-year-old female, G1P0, presented to our clinic for an initial prenatal visit at 17 weeks and 3 days. Her medical history was significant for hemoglobinopathy AS and QuantiFERON positive without evidence of active tuberculosis. The initial sonogram at 18 weeks and 5 days gestation identified an anterior placenta, missing part of the left tibia and fibula, absence of the left foot, and floating bands strongly suggestive of amniotic bands (Figure 5), ending in a small extension of 

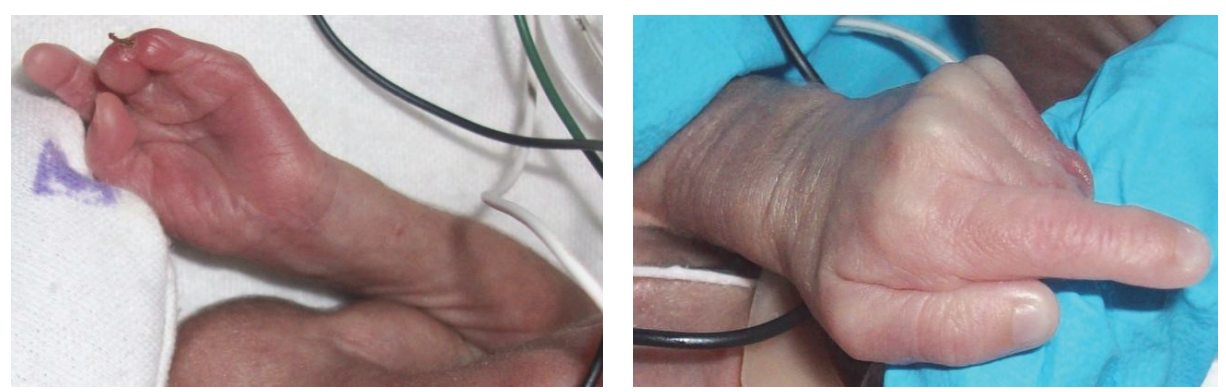

FIGURE 1: Left hand: newborn with visible bands tethering fingers together. Amniotic bands have resulted in syndactyly, amputation, adhesion, and band indentation. Thumb and index finger are intact; only proximal part of 3rd and 4th digit is present; 5th digit is completely missing.

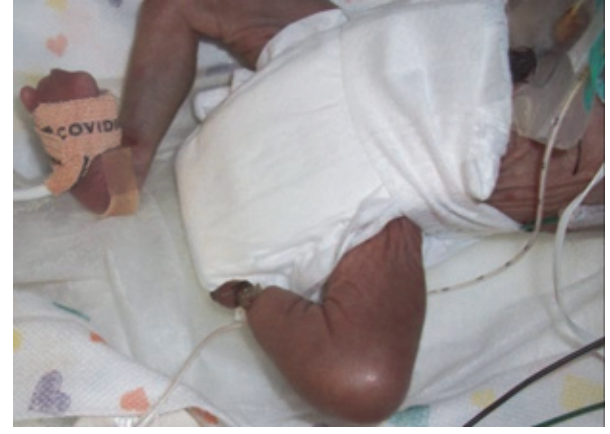

FIGURE 2: Left leg with amputation due to amniotic band. Right leg with only the 5 th digit.

tissue of approximately $0.5-1.0 \mathrm{~cm}$ in length and $0.5 \mathrm{~cm}$ in width (Figures 2 and 4).

At 21 weeks in the emergency department, the fetus was in breech presentation with oligohydramnios and premature rupture of membranes (PPROM). After appropriate counseling about the outcome, the patient declined immediate pregnancy termination and elected antepartum admission for expectant management of PPROM. Intravenous hydration and antenatal corticosteroids were started at 27 weeks, due to nonreassuring fetal status. A 750-gram male infant was delivered via classical cesarean section with an Apgar score of 6 and 7 at 1 and 5 minutes, respectively. The immediate neonatal course was complicated by immaturity as manifested by respiratory distress syndrome, leading to intubation and admission to the neonatal intensive care unit.

After thirty-six days of life, he is active and extubated, with equal breath sounds bilaterally, weighting 1120 grams and tolerating oral feeding while weaning from Total Parenteral Nutrition. Plans for future long-term care and physical therapy of his upper and lower limb abnormalities were initiated (Figures 1-4).

\section{Discussion}

There are two main theories as to the etiology of amniotic band syndrome. Originally, the intrinsic theory on inherent developmental defects was proposed by Streeter $[12,13]$. The most likely explanation, which is supported by the majority of current authors, is the extrinsic theory proposed by Torpin

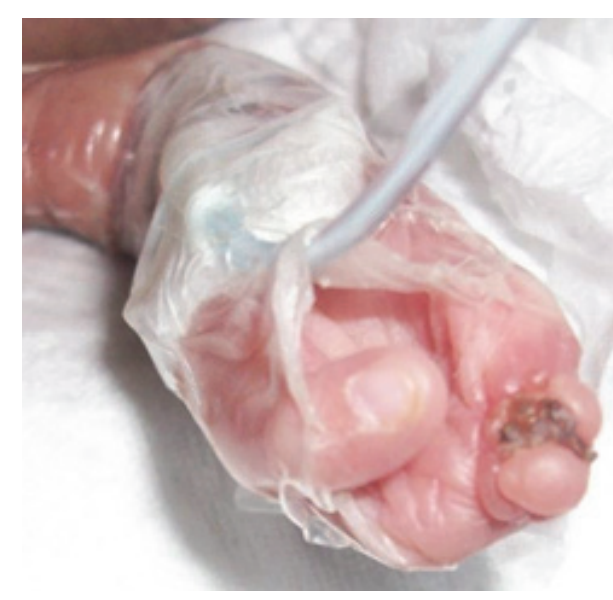

FIGURE 3: Right hand, only thumb present.

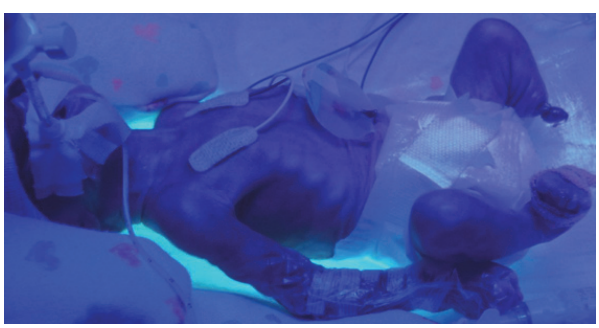

FIGURE 4: Under phototherapy, amputated left lower extremities are noted.

[14-16]. It suggests adhesive bands around fetal limbs, due to slippage of the ruptured amnion from the chorion, leading to oligohydramnios and growth abnormalities $[7,15,17,18]$.

The diagnosis is based on ultrasound visualization of amniotic bands in an asymmetric distribution or deformities in a "random" nonembryonic distribution. These findings may be confirmed by fetal MRI, which is often ordered as a complimentary measure upon consideration of fetal surgery $[13,19,20]$. Amniotic bands are now being successfully released fetoscopically through minimally invasive surgery [19]. The intrauterine procedure is delicate and the decision to perform this surgery must be carefully weighed against the potential risks to the mother and the fetus versus continuing or terminating pregnancy [21-24]. 


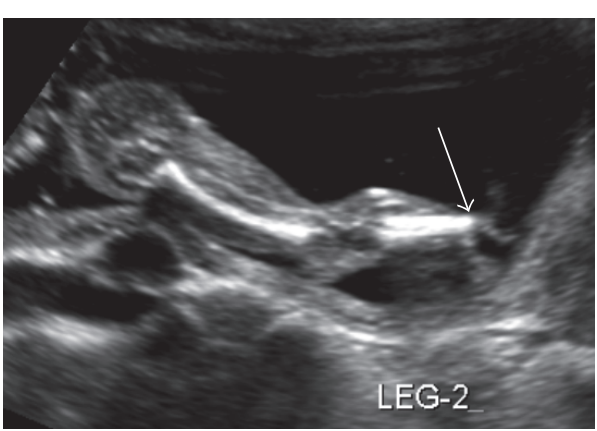

(a)

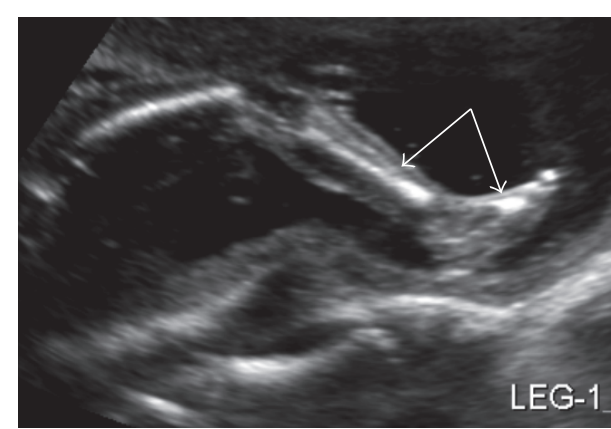

(b)

FIGURE 5: Official ultrasound on 1/13/2016: one lower extremity (left leg, leg 2 in (a)) is incomplete, the tibia fibula terminates abruptly and a foot is not seen. The other lower extremity (right leg, leg 1 in (b)) shows appropriate length for femur, tibia fibula, and a well formed foot. Noted during the examination are floating bands strongly suggestive of amniotic bands.

Constricted bands are usually confined to the skin and soft tissues but at times can reach depths that cut off normal vascular and lymph supply, causing venous congestion, ischemia, chronic edema, clubfoot, and fractures of the afflicted areas [25-29]. When not diagnosed until postpartum, bands that interfere with drainage of the limb resulting in venous congestion or lymphedema can produce extreme pain, due to peripheral nerve compression requiring early surgical intervention repeated over several stages to improve long-term function $[1,28,30-33]$.

\section{Conclusion}

The most widely held theory describes early rupture of the amnion and entanglement of fetal parts by amniotic bands, leading to congenital abnormalities most consistent with pathognomonic features of amniotic bands and limb/digit abnormalities or amputations. Due to the perinatal complications associated with intrauterine band lysis, multidisciplinary meeting consisting of family, obstetricians, neonatologist, psychologist, social worker, and other relevant entities should take place to discuss the options for continuation of pregnancy, perinatal hospice care, and pregnancy termination. Extrauterine surgical intervention should be performed within weeks to months, with a dedicated follow-up by family members of the newborn, pediatrics, and surgical teams to ensure functionality of the limb recently constricted, unless there is a vascular compromise, which would mandate an immediate surgical intervention. Due to the diverse presentation of amniotic band syndrome or ADAM complex, management should be tailored to the individual, taking into account the gestational age and birth defects at presentation.

\section{Competing Interests}

The authors did not report any potential conflict of interests.

\section{Acknowledgments}

The authors would like to thank Ms. Judith Wilkinson, Medical Librarian at Lincoln Medical and Mental Health Center Science Library, for providing the reference articles.

\section{References}

[1] J. H. Walter Jr., L. R. Goss, and A. T. Lazzara, "Amniotic band syndrome," Journal of Foot and Ankle Surgery, vol. 37, no. 4, pp. 325-333, 1998.

[2] B. Poeuf, P. Samson, and G. Magalon, "Syndrome des brides amniotiques," Chirurgie de la Main, vol. 27, pp. S136-S147, 2008 (French).

[3] K. Tada, K. Yonenobu, and A. B. Swanson, "Congenital constriction band syndrome," Journal of Pediatric Orthopaedics, vol. 4, no. 6, pp. 726-730, 1984.

[4] H. Satake, T. Ogino, K. Iba, T. Watanabe, and J. Eto, "Metacarpal hypoplasia associated with congenital constriction band syndrome," Journal of Hand Surgery, vol. 37, no. 4, pp. 760-763, 2012.

[5] T. R. Light and J. A. Ogden, "Congenital constriction band syndrome. Pathophysiology and treatment," Yale Journal of Biology and Medicine, vol. 66, no. 3, pp. 143-155, 1993.

[6] G. Askins and E. Ger, "Congenital constriction band syndrome," Journal of Pediatric Orthopaedics, vol. 8, no. 4, pp. 461-466, 1988.

[7] K. Kawamura and K. C. Chung, "Constriction band syndrome," Hand Clinics, vol. 25, no. 2, pp. 257-264, 2009.

[8] E. Koskimies, J. Syvänen, Y. Nietosvaara, O. Mäkitie, and N. Pakkasjärvi, "Congenital constriction band syndrome with limb defects," Journal of Pediatric Orthopaedics, vol. 35, no. 1, pp. 100103, 2015.

[9] M. O’Driscoll, C. Peckham, and B. Kerr, "Four limb syndactyly, constriction rings and skin tags; amniotic bands or disorganization-like syndrome," Clinical Dysmorphology, vol. 17, no. 4, pp. 255-258, 2008.

[10] A. Agarwal, A. Shaharyar, and A. Kumar, "Clubfoot associated with congenital constriction band: the ponseti method perspective," Foot \& Ankle Specialist, vol. 8, no. 3, pp. 230-233, 2015.

[11] W. L. A. Fung, N. J. Butcher, G. Costain et al., "Practical guidelines for managing adults with 22q11.2 deletion syndrome," Genetics in Medicine, vol. 17, no. 8, pp. 599-609, 2015.

[12] G. L. Streeter, Focal Deficiencies in Fetal Tissues and Their Relation to Intra-Uterine Amputation, vol. 22, no. 126 of Contributions to Embryology, Carnegie Institution of Washington, Washington, DC, USA, 1930.

[13] K. Gupta, B. Venkatesan, T. Chandra, K. Rajeswari, and T. K. Renuka Devi, "Amniotic band syndrome with sacral agenesis and umbilical cord entrapment: a case report emphasizing the 
value of evaluation of umbilical cord," Journal of Radiology Case Reports, vol. 9, no. 3, pp. 12-19, 2015.

[14] P. Devi, P. Cicy, R. Thambi, and U. Poothiode, "Significance of fibrotic bands in utero-amniotic band sequence with limb body wall complex: a rare case of fetal autopsy," Indian Journal of Pathology and Microbiology, vol. 58, no. 4, pp. 528-530, 2015.

[15] G. Das, S. Gayen, S. Bandyopadhyay, and D. Das, "Ethmocephaly with amniotic band syndrome," Middle East African Journal of Ophthalmology, vol. 19, no. 4, pp. 429-431, 2012.

[16] R. Torpin, "Amniochorionic mesoblastic fibrous strings and amnionic bands: associated constricting fetal malformations or fetal death," American Journal of Obstetrics and Gynecology, vol. 91, no. 1, pp. 65-75, 1965.

[17] P. Cignini, C. Giorlandino, F. Padula, N. Dugo, E. V. Cafà, and A. Spata, "Epidemiology and risk factors of amniotic band syndrome, or ADAM sequence," Journal of Prenatal Medicine, vol. 6, no. 4, pp. 59-63, 2012.

[18] Y. S. Siddiqui, A. Q. Khan, M. Abbas, and H. Q. Siddiqui, "A child with congenital constriction bands," Saudi Medical Journal, vol. 31, no. 11, pp. 1276-1277, 2010.

[19] J. Neuman, M. A. Calvo-Garcia, B. M. Kline-Fath et al., "Prenatal imaging of amniotic band sequence: utility and role of fetal MRI as an adjunct to prenatal US," Pediatric Radiology, vol. 42, no. 5, pp. 544-551, 2012.

[20] L. Sentilhes, E. Verspyck, S. Patrier, D. Eurin, J. Lechevallier, and L. Marpeau, "Amniotic band syndrome: pathogenesis, prenatal diagnosis and neonatal management," Journal de Gynécologie Obstétrique et Biologie de la Reproduction, vol. 8, part 1, pp. 693704, 2003 (French).

[21] P. Javadian, A. A. Shamshirsaz, S. Haeri et al., "Perinatal outcome after fetoscopic release of amniotic bands: a singlecenter experience and review of the literature," Ultrasound in Obstetrics \& Gynecology, vol. 42, no. 4, pp. 449-455, 2013.

[22] L. Sentilhes, E. Verspyck, D. Eurin et al., "Favourable outcome of a tight constriction band secondary to amniotic band syndrome," Prenatal Diagnosis, vol. 24, no. 3, pp. 198-201, 2004.

[23] D. Ronderos-Dumit, F. Briceño, H. Navarro, and N. Sanchez, "Endoscopic release of limb constriction rings in utero," Fetal Diagnosis and Therapy, vol. 21, no. 3, pp. 255-258, 2006.

[24] M.-J. Marron-Corwin and A. D. Corwin, "When tenderness should replace technology: the role of perinatal hospice," NeoReviews, vol. 9, no. 8, pp. e348-e352, 2008.

[25] C. Zaré, I. A. Traoré, P. W. H. Dakouré et al., "Amniotic band syndrome at Bobo Dioulasso university teaching hospital (Burkina- Faso): about two cases," Pan African Medical Journal, vol. 22, article 187, 2015.

[26] A. Rodrigues, C. Araújo, R. Carvalho, M. A. Melo, L. Pinto, and L. M. da Graça, "Limb constriction secondary to pseudoamniotic band syndrome after selective fetoscopic laser surgery: report of a case with a favorable outcome," Fetal Diagnosis and Therapy, vol. 32, no. 4, pp. 288-291, 2012.

[27] R. Jaiman, A. N. Gangopadhyay, D. K. Gupta et al., "A child presented with bilateral congenital constriction ring in lower extremity: a case report," Cases Journal, vol. 2, Article ID 7772, 2009.

[28] K. Ozkan, K. Unay, B. Goksan, K. Akan, N. Aydemir, and N. K. Ozkan, "Congenital constriction ring syndrome with foot deformity: two case reports," Cases Journal, vol. 2, article 6696, 2009.

[29] R. J. Hernández Herrera, Y. M. Padilla Martínez, and D. M. Esquivel Izaguirre, "Pseudosyndactyly and amputation as the main features of the amniotic band syndrome," Boletín Médico del Hospital Infantil de México, vol. 68, no. 1, pp. 50-52, 2011.

[30] S. L. Moran, M. Jensen, and C. Bravo, "Amniotic band syndrome of the upper extremity: diagnosis and management," Journal of the American Academy of Orthopaedic Surgeons, vol. 15, no. 7, pp. 397-407, 2007.

[31] R. Durga and T. K. Renukadevi, "Amniotic band syndrome-a dreaded condition," Journal of Clinical and Diagnostic Research, vol. 10, no. 1, pp. QD04-QD05, 2016.

[32] N. S. Ciloglu and N. Gumus, "A rare form of congenital amniotic band syndrome: total circular abdominal constriction band," Archives of Plastic Surgery, vol. 41, no. 3, pp. 290-291, 2014.

[33] P. Shetty, L. T. Menezes, L. F. Tauro, and K. A. Diddigi, "Amniotic band syndrome," Indian Journal of Surgery, vol. 75, no. 5, pp. 401-402, 2013. 


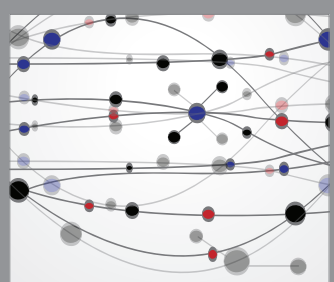

The Scientific World Journal
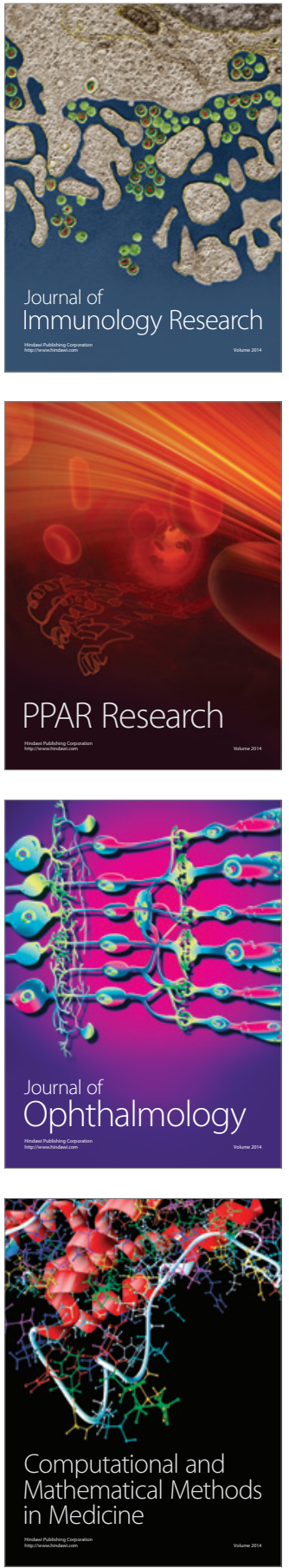

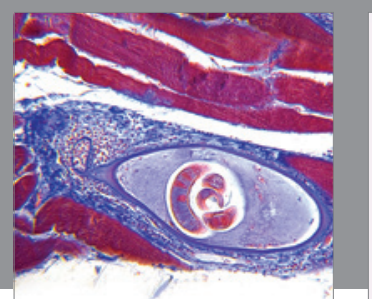

Gastroenterology Research and Practice

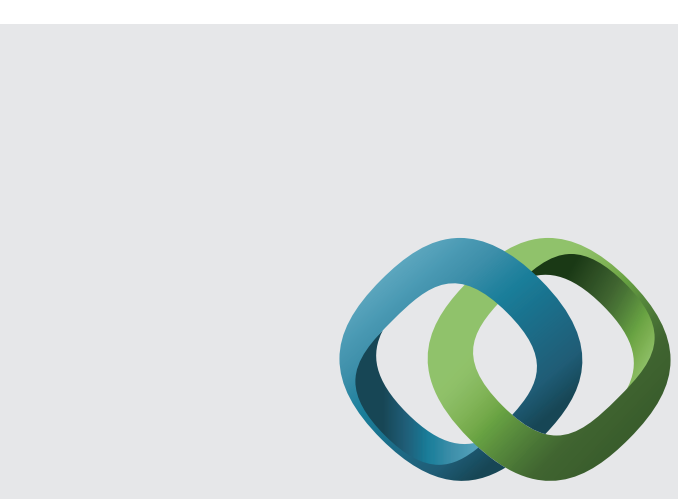

\section{Hindawi}

Submit your manuscripts at

http://www.hindawi.com
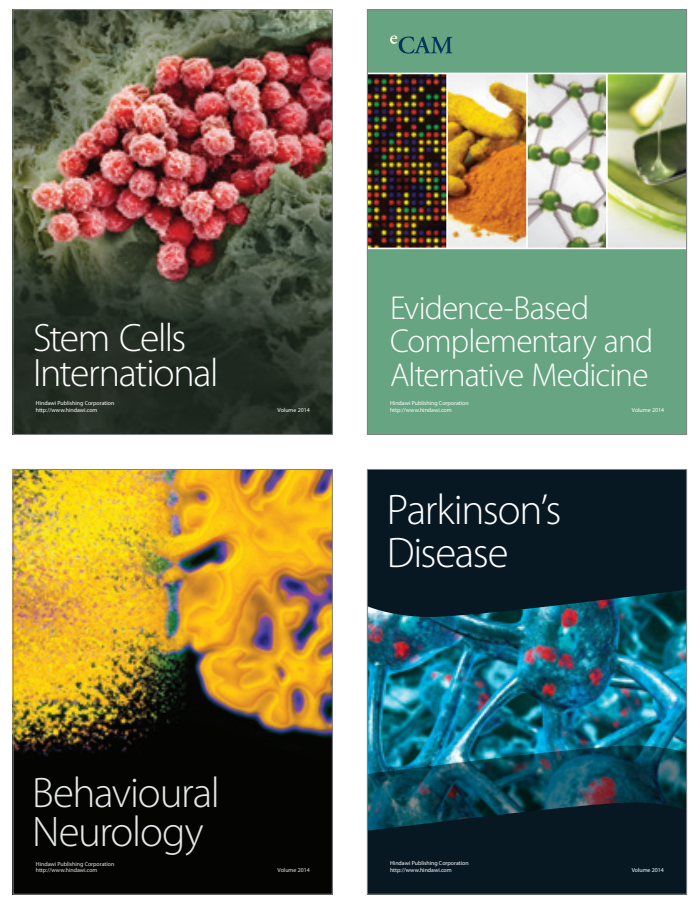
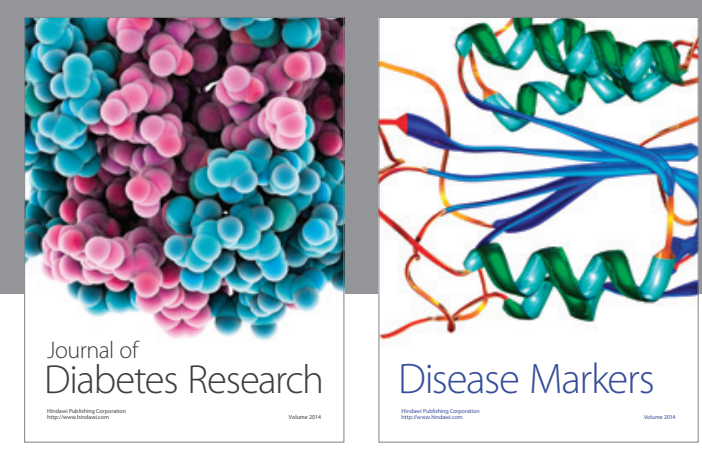

Disease Markers
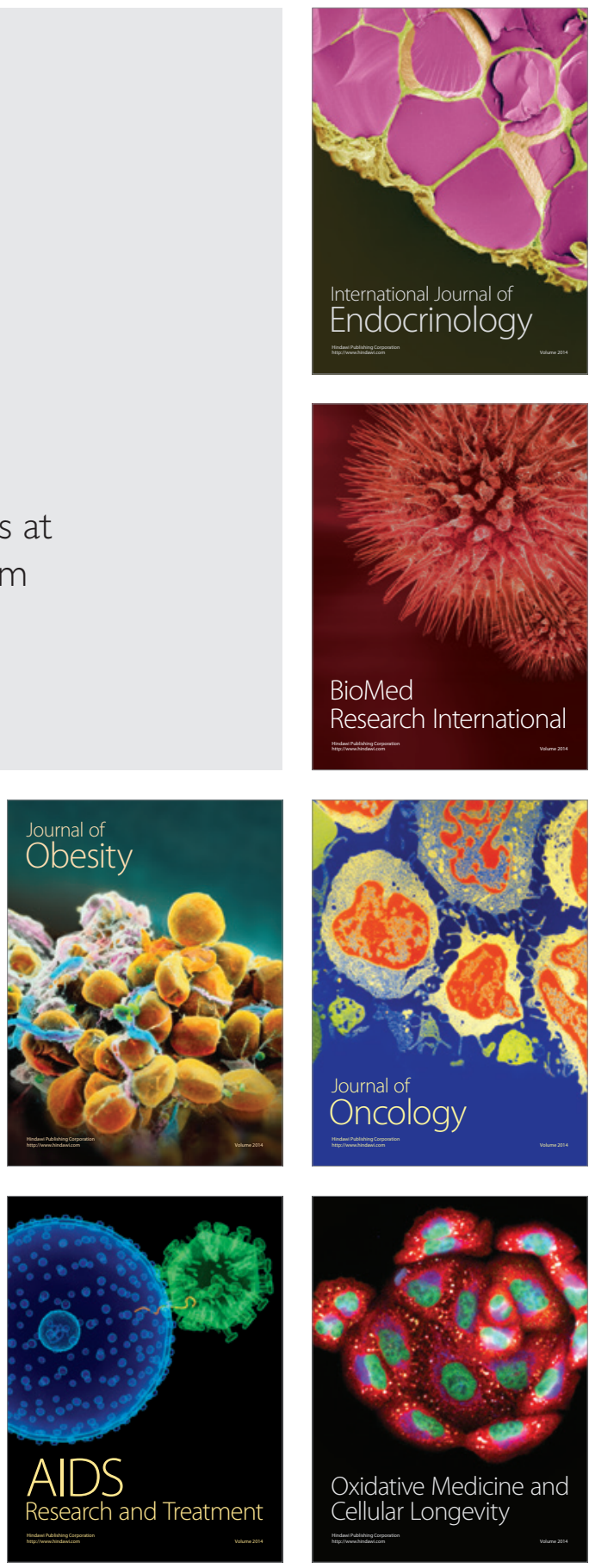